\title{
La influencia de las características de las viviendas de segunda mano en sus precios de venta: evidencias en el mercado alicantino
}

\section{The influence of the characteristics of second-hand properties on their asking prices: evidence in the Alicante market}

\author{
V.R. Pérez-Sánchez ${ }^{(*)}, \underline{\text { R.T. Mora-García }}{ }^{(*)}$, J.C. Pérez-Sánchez ${ }^{(*)}$, M.F. Céspedes-López ${ }^{(*)}$
}

\section{RESUMEN}

En este artículo se estima el impacto que tienen las características de las viviendas alicantinas de segunda mano, en el precio de venta. Para desarrollar este trabajo, se ha utilizado información procedente de los portales inmobiliarios, que ofrecen datos relativos a cualidades que presentan las viviendas, el edificio, la situación geográfica y los precios de venta. El análisis se centra en la provincia de Alicante, utilizándose una regresión hedónica en la que las características que presentan las viviendas y la ubicación actúan como variables independientes y el precio de venta como dependiente. Los resultados muestran diferencias significativas en los precios de venta de las viviendas en función de las características y la ubicación, sugiriendo unos precios mayores para las viviendas situadas en las comarcas litorales del norte de Alicante, o para las que tienen piscina, jardín o garaje. Sin embargo, las situadas al sur o en el interior muestran un menor precio.

Palabras clave: Viviendas, características, precios, portales inmobiliarios, Alicante.

\section{ABSTRACT}

This paper estimates the impact that the characteristics of second-hand homes in Alicante have on the asking price. In order to carry out this research, information has been used from real estate portals, which offer information such as the characteristics of dwellings, the building, their geographical location and asking prices. The analysis is developed in the province of Alicante geographic context. A hedonic regression is estimated in which the dwellings characteristics and location act as independent variables, and the asking price as a dependent value. The results show significant differences in the dwelling asking price depending on its characteristics and location, suggesting higher prices for dwellings: located in the coastal regions of the north of Alicante, that have a swimming pool, garden or parking space. However, dwellings with lower asking prices are: those located in southern and inland regions of the province.

Keywords: Housing, characteristics, prices, real estate portals, Alicante.

(*) Universidad de Alicante (España).

Persona de contacto/Corresponding author: rtmg@ua.es (R.T. Mora-García).

ORCID: https://orcid.org/oooo-00o3-1045-3671 (V.R. Pérez-Sánchez); https://orcid.org/oooo-0oo2-5581-5456

(R.T. Mora-García); https://orcid.org/oooo-0001-8524-3623 (J.C. Pérez-Sánchez); https://orcid.org/oooo-0002-37248267 (M.F. Céspedes-López).

Cómo citar este artículo/Citation: Pérez-Sánchez, V.R.; Mora-García, R.T.; Pérez-Sánchez, J.C.; Céspedes-López, M.F. (2020). La influencia de las características de las viviendas de segunda mano en sus precios de venta: evidencias en el mercado alicantino. Informes de la Construcción, 72(558): e345. https://doi.org/10.3989/ic.68059.

Copyright: (c) 2020 CSIC. Este es un artículo de acceso abierto distribuido bajo los términos de la licencia de uso y distribución Creative Commons Reconocimiento 4.0 Internacional (CC BY 4.0). 


\section{INTRODUCCIÓN}

El estudio contribuye al conocimiento del mercado inmobiliario alicantino de viviendas de segunda mano, especialmente se analiza la relación del precio de venta de las viviendas, con las características que éstas presentan. Según los datos del Ministerio de Fomento sobre el número de transacciones inmobiliarias, la vivienda usada en el mercado alicantino es relevante, dado que las operaciones en este tipo de viviendas superan a las de vivienda nueva en los últimos nueve años. Además, a partir de 2008 la importancia relativa de las transacciones de este tipo de vivienda se incrementa como consecuencia de la caída de las operaciones de vivienda nueva. Esta reducción hace que en los cuatro últimos años (2014-2017), el número de transacciones de vivienda usada suponga más del $87 \%$ de las operaciones que se realizan en el mercado inmobiliario alicantino, evidenciándose la relevancia de este tipo de vivienda.

En este trabajo se utiliza la metodología basada en el modelo de precios hedónicos, que forma un cuerpo sustancial de investigación histórica utilizado para tratar de explicar el valor de la vivienda en función de la valoración de sus componentes (1). Estos autores advierten que los resultados de los modelos de precios hedónicos son difícilmente generalizables para diferentes ubicaciones geográficas, a pesar de ello, subrayan la gran utilidad que presenta para comprender mejor el funcionamiento de un mercado en particular.

En el caso español, pueden citarse varios trabajos como el de Nicodemo y Raya (2) donde se estudia el cambio en los precios de la vivienda en las principales ciudades españolas mediante estimaciones cuantílicas en el periodo 2004-07. McGreal y Taltavull (3) estudian la variación de los precios de la vivienda en siete provincias españolas entre 1995 y 2010, evaluándose cómo los precios implícitos varían con el tiempo y el espacio, tratando de identificar las características más importantes que influyen en los precios. Taltavull (4) analiza la relación que existe entre los precios de la vivienda y los factores económicos y demográficos determinantes de la demanda, para ello utiliza datos de panel para 71 ciudades españolas de más de 100.000 habitantes. Bengochea-Morancho (5) estudia el vínculo entre los precios de las viviendas y las dotaciones en zonas verdes urbanas en la ciudad de Castellón, o Chasco-Yrigoyen y Sánchez-Reyes (6) que analizan el impacto de la contaminación atmosférica y el ruido sobre el precio de la vivienda en la zona centro de Madrid.

La metodología de los precios hedónicos se basa en la idea de que la utilidad que proporciona una vivienda, se deriva de la que aportan las características que posee. Zietz indican que el análisis de regresión hedónica es utilizado normalmente para identificar el efecto marginal que tiene un conjunto de características sobre el precio de la vivienda. Esa multitud de características presentes en los bienes heterogéneos, como es el caso de una vivienda, pueden afectar a su valor, permitiendo la metodología hedónica estimar la contribución de las mismas en el precio (1).

La metodología de los precios hedónicos ha sido utilizada con anterioridad al mercado de la vivienda en el de los automóviles, destacando varios autores el trabajo de Court (8) por incorporar mejoras a la metodología del análisis. En el mercado de la vivienda, la primera aplicación de la metodología de los precios hedónicos se encuentra en los trabajos de Ridker y Henning (9), siendo los primeros autores que trataron los determinantes del valor de las viviendas, haciendo especial referencia a cuestiones medioambientales, como la contaminación del aire en un área concreta (10). No obstante, no será hasta el trabajo de Rosen (11) cuando se proporcione un tratamiento unificado del modelo teórico de los mercados implícitos que subyacen en el modelo de precios hedónicos, llegando a ser generalmente aceptado como el paradigma del enfoque hedónico $(10,12)$.

La literatura muestra como los modelos hedónicos han utilizado una gran multitud de variables para recoger las características que tienen las viviendas, no solamente relacionadas con componentes elementales, como pueden ser la superficie, el número de baños o el número de dormitorios, por citar algunas, sino otras que no son tan obvias, como la proximidad a centros educativos, a zonas verdes, a hospitales o a zonas comerciales. Dentro de esta segunda tipología de características, los modelos también han analizado cómo afectan al precio de venta cuestiones como son la proximidad a un vertedero o a líneas de alta tensión.

Sirmans et al. (1) analizaron ciento veinticinco artículos que utilizaron modelos hedónicos, realizando a modo de síntesis, un listado en el que recogen el número de veces que aparecen las veinte características principales que han sido utilizadas en estos modelos, así como el signo con el que aparecen. Cuestiones como la superficie de las viviendas, la antigüedad, la existencia de chimenea, o de plaza de aparcamiento aparecen en sesenta o más de los modelos consultados.

En la Tabla 1 se recoge una revisión, limitada al objetivo de este estudio, de variables utilizadas por otros autores para la determinación del precio de la vivienda, recogiendo sólo las que han resultado estadísticamente significativas.

El objetivo principal de este trabajo es analizar y cuantificar la influencia que tienen las características que presentan las viviendas de segunda mano situadas en la provincia de Alicante en el precio de venta. Para alcanzarlo, se define un mo-

Tabla 1. Variables determinantes del precio de la vivienda.

\begin{tabular}{|c|c|c|}
\hline Categoría & Característica & Referencias \\
\hline $\begin{array}{c}\text { Tipología } \\
\text { de la vivienda }\end{array}$ & $\begin{array}{l}\text { Piso, ático, dúplex } \\
\text { y/o estudio }\end{array}$ & $(5,6,13,14,15)$ \\
\hline \multirow{9}{*}{$\begin{array}{l}\text { Características } \\
\text { interiores }\end{array}$} & Núm. de baños & $(5,13,14,15,16,17)$ \\
\hline & Núm. de dormitorios & $(5,13,14,15,18)$ \\
\hline & Superficie vivienda & $\begin{array}{c}(2,3,5,6,10,13,14,15 \\
17,18,19,20)\end{array}$ \\
\hline & Terraza & $(3,5,14)$ \\
\hline & Aire acondicionado & $(17,18)$ \\
\hline & Armarios & $(15,20)$ \\
\hline & Planta & $(2,6,15,17,18,19)$ \\
\hline & Antigüedad & $\begin{array}{c}(2,3,5,13,14,15,20 \\
21)\end{array}$ \\
\hline & $\begin{array}{l}\text { Estado (nueva, } \\
\text { normal, para reformar) }\end{array}$ & $(6,14,15,17,18)$ \\
\hline \multirow{5}{*}{$\begin{array}{l}\text { Características } \\
\text { exteriores }\end{array}$} & Ascensor & $\begin{array}{c}(2,3,5,13,14,15,17 \\
20)\end{array}$ \\
\hline & Jardín & $(13,22)$ \\
\hline & Piscina en el edificio & $(13,17)$ \\
\hline & Plaza garaje & $(5,10,14,16)$ \\
\hline & Trastero & $(5,10,15,19)$ \\
\hline Orientación & Norte, sur, este y oeste & $(3,13)$ \\
\hline Ubicación & $\begin{array}{l}\text { Ubicación en el } \\
\text { territorio o ciudad }\end{array}$ & $(15,18,19)$ \\
\hline
\end{tabular}


delo en el que el precio se hace depender de un conjunto de características, y se estima utilizando el método de regresión por mínimos cuadrados ordinarios.

Los resultados muestran que existen algunas características como son la orientación, el número de baños, la existencia de ascensor, la disponibilidad de plaza de garaje, o de piscina, que tienen un impacto significativo en los precios, y que ese impacto es diferente en función de la comarca en la que se sitúa la vivienda.

El resto del documento se organiza de la siguiente manera. La sección segunda presenta los materiales y el método utilizado, en la sección tercera se ofrecen los resultados, en la cuarta la discusión y en la quinta y última sección se sintetizan las conclusiones obtenidas.

\section{MATERIALES Y MÉTODOS}

El diseño de la investigación es no experimental, de tipo exploratorio y correlacional, de corte transversal de variables no manipuladas experimentalmente.

\subsection{Metodología}

Se ha elaborado una base de datos de inmuebles a partir de un portal inmobiliario, recogiendo información como el precio, las características de los inmuebles y la localización espacial. La muestra de observaciones ha sido sometida a un análisis de valores atípicos univariados, descartando aquellos casos que difieran más o menos de 3 desviaciones estándar en su respectivas variables tipificadas (puntuaciones $Z$ ), posteriormente se han analizado los valores atípicos multivariados utilizando la distancia de Mahalanobis.

En un primer paso se estudia la matriz de correlaciones bivariadas y los gráficos de dispersión, para identificar la existencia de linealidad entre las variables. Posteriormente se realiza un análisis de regresión por mínimos cuadrados ordinarios (MCO) mediante el método por pasos sucesivos para la selección de variables estadísticamente significativas. Puesto que la base de datos tiene observaciones con datos incompletos o faltantes, se ha decidido utilizar la selección de casos por parejas o pairwise. La posible presencia de multicolinealidad se estudia a partir de los coeficientes de correlación, el factor de inflación de la varianza $(V I F)$ y los índices de condición. La independencia de las observaciones muestrales se contrasta mediante el estadístico Durbin-Watson. A partir de un gráfico de dispersión de los residuos se evalúa la presencia de heterocedasticidad, y mediante un diagrama de frecuencias la normalidad de los residuos.

\subsection{Datos}

Para poder desarrollar este trabajo se han utilizado datos procedentes del portal inmobiliario idealista, el cual ofrece anuncios de viviendas que se pueden comprar, alquilar o compartir a nivel nacional. En referencia al número de anuncios publicitados, se supera el millón y medio en España. Con respecto a la provincia de Alicante, se han extraído datos de 94.222 anuncios, entre junio y agosto de 2017. Dado que estas observaciones recogen distintos tipos de vivienda y operaciones, tanto de venta (94,3\%) como de alquiler (5,7\%), en este trabajo se han utilizado solamente aquellas que hacen referencia a operaciones de venta para viviendas de tipología multifamiliar (piso, ático, dúplex y estudio) con un total del 62,4\% de las observa- ciones, no habiéndose considerado las viviendas de tipo unifamiliar $(31,9 \%)$ ni en alquiler. Como consecuencia de que la información disponible en el portal inmobiliario se genera a partir de los datos que introducen los propios anunciantes, se ha realizado un trabajo previo de filtrado ya que se ha comprobado la inconsistencia de datos en algunas observaciones que aparecen. Por ejemplo, existen viviendas anunciadas con diez habitaciones y solamente una superficie de noventa metros cuadrados, o viviendas con novecientos metros de superficie y tres habitaciones. Estos valores han sido descartados al ser considerados atípicos. Como resultado de este trabajo inicial, la base de datos revisada se ha reducido en 1.610 observaciones, dejando la muestra útil en 57.182 inmuebles.

La base de datos recuperada del portal inmobiliario tiene ciertas limitaciones, ya que no cuenta con determinadas variables importantes en la literatura, como la antigüedad o el estado de conservación, además de que no todas las observaciones tienen datos completos en todas las variables. En una revisión de la literatura realizada por los autores sobre 93 artículos de revista, en el $45 \%$ de los casos no utilizaron la antigüedad, véanse por ejemplo $(16,22,23)$. De los 57.182 inmuebles, el 34,2\% dispone de datos completos, mientras que en el otro $65,8 \%$ de la muestra pueden faltar datos en una o más variables.

En referencia a la configuración de la información, la mayoría de las observaciones $(89,7 \%)$, son viviendas tipo piso situadas en edificios residenciales, ubicados mayoritariamente en Alicante y el Bajo Segura (34,0 y 20,5\%).

Con respecto a la distribución de los precios (Figura 1.b), se puede observar que la franja litoral concentra precios unitarios $\left(€ / \mathrm{m}^{2}\right)$ mayores que el resto de la provincia alicantina. La Tabla 2 muestra como solamente en tres de las nueve comarcas alicantinas (las tres costeras), el precio medio por comarca supera al medio provincial.

La Tabla 3 muestra las 29 variables (o características) que se han definido, organizadas en cinco grupos, basados en la clasificación propuesta por Sirmans et al. (1). El primero hace referencia a la tipología de la vivienda, el segundo a las características interiores que presenta cada observación, el tercero a las características exteriores del edificio en el que se ubica la vivienda, el cuarto a la orientación de las fachadas de la vivienda, y en quinto y último lugar la ubicación geográfica de la vivienda. (Ver Tabla 6 para una mayor descripción de las variables).

Tabla 2. Precios medios $(€)$ y unitarios $\left(€ / \mathrm{m}^{2}\right)$, por provincia y comarca.

\begin{tabular}{|c|c|c|c|c|}
\hline & $N$ & Precio medio $€$ & $\begin{array}{c}\text { Unitario } \\
\mathbf{\epsilon} / \mathbf{m}^{2}\end{array}$ \\
\hline \multicolumn{2}{|r|}{ Provincial } & 57.182 & $130.745(83.598)$ & $1.374(717)$ \\
\hline \multirow{5}{*}{ 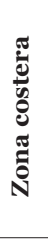 } & Marina Baja & 7.185 & $160.746(87.866)$ & $1.819(709)$ \\
\hline & Marina Alta & $7 \cdot 521$ & $160.299(89.925)$ & $1.670(769)$ \\
\hline & Alicante & 19.449 & $144.702(89.287)$ & $1.377(686)$ \\
\hline & Bajo Vinalopó & 7.198 & $111.565(68.625)$ & $1.152(602)$ \\
\hline & Bajo Segura & 11.747 & $103.182(61.005)$ & $1.284(626)$ \\
\hline \multirow{4}{*}{ 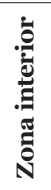 } & Condado & 167 & $82.823(48.232)$ & 777 (333) \\
\hline & Alcoy & 1.496 & $71.026(44.936)$ & $702(349)$ \\
\hline & Alto Vinalopó & 538 & $71.010(41.812)$ & $662(334)$ \\
\hline & Medio Vinalopó & 1.881 & $68.046(39.423)$ & $654(327)$ \\
\hline
\end{tabular}

Notas: Desviación estándar entre paréntesis, $N=$ tamaño de la muestra. 


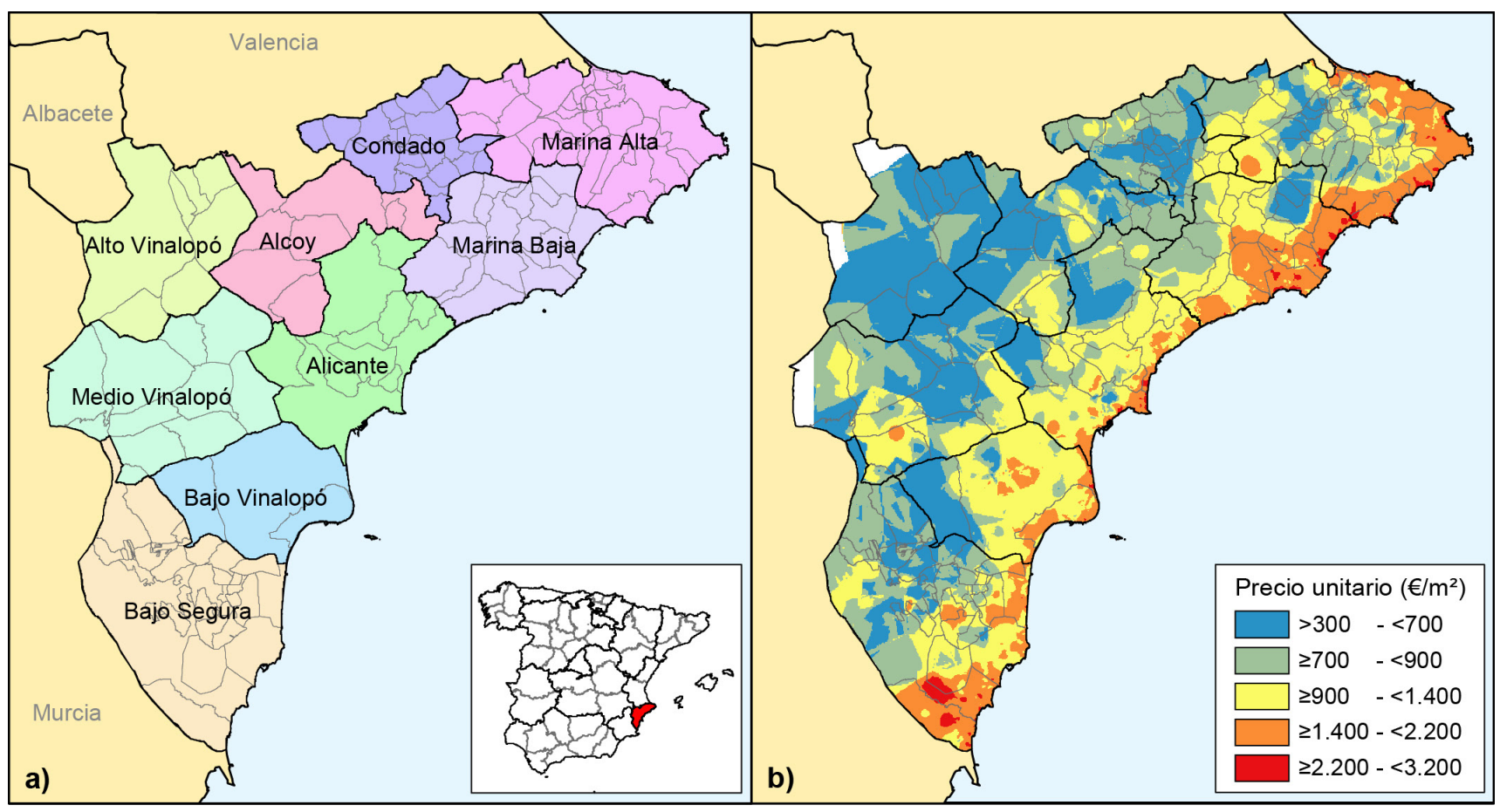

Figura 1. a) Comarcas de la provincia de Alicante y b) mapa de densidad kernel con precios unitarios de viviendas multifamiliares (€/ $\left.\mathrm{m}^{2}\right)$.

Tabla 3. Variables utilizadas y ordenadas según agrupación.

\begin{tabular}{|l|l|l|l|l|}
\hline \multicolumn{1}{|c|}{ Tipología } & $\begin{array}{c}\text { Características } \\
\text { interiores }\end{array}$ & $\begin{array}{c}\text { Características } \\
\text { exteriores }\end{array}$ & \multicolumn{1}{|c|}{ Orientación } & \multicolumn{1}{|c|}{ Ubicación } \\
\hline piso $^{\mathrm{b}}$ & num_baños $^{\mathrm{a}}$ & ascensor $^{\mathrm{b}}$ & norte $^{\mathrm{b}}$ & Alicante $^{\mathrm{b}}$ \\
\hline atico $^{\mathrm{b}}$ & num_dormit $^{\mathrm{a}}$ & jardin $^{\mathrm{b}}$ & sur $^{\mathrm{b}}$ & Marina_Baja $^{\mathrm{b}}$ \\
\hline duplex $^{\mathrm{b}}$ & meconstr $^{\mathrm{a}}$ & piscina $^{\mathrm{b}}$ & este $^{\mathrm{b}}$ & Marina_Alta $^{\mathrm{b}}$ \\
\hline estudio $^{\mathrm{b}}$ & terraza $^{\mathrm{b}}$ & plaza_garaje $^{\mathrm{b}}$ & oeste $^{\mathrm{b}}$ & Bajo_Vinalopo $^{\mathrm{b}}$ \\
\hline & aire_acond $^{\mathrm{b}}$ & trastero $^{\mathrm{b}}$ & & Bajo_Segura $^{\mathrm{b}}$ \\
\hline & armarios $^{\mathrm{b}}$ & & & Medio_Vinalopo $^{\mathrm{b}}$ \\
\hline & fachada_int $^{\mathrm{b}}$ & & & Alcoy $^{\mathrm{b}}$ \\
\hline & & & & Condado $^{\mathrm{b}}$ \\
\hline & & & & Alto_Vinalopo $^{\mathrm{b}}$ \\
\hline & & & & \\
\hline
\end{tabular}

Notas: ${ }^{\text {a }}$ variables cuantitativas; ${ }^{\mathrm{b}}$ variables ficticias (1 posee la característica, o no la posee).

Se han definido cuatro variables ficticias para identificar la tipología de las viviendas multifamiliares (piso, ático, dúplex y estudio), codificadas con un valor de 1 cuando poseen dicha característica y o cuando no la tienen. Como características interiores se han definidos tres variables cuantitativas: el número de baños, número de dormitorios y metros cuadrados construidos; y otras cuatro de tipo ficticias: si la vivienda tiene o no terraza, aire acondicionado, armarios empotrados, y si la fachada da a interior de manzana o a fachada exterior (variable "fachada_int"). Como características exteriores se establecen cinco variables, si la vivienda cuenta con plaza de garaje, o trastero, y si el edificio tiene ascensor, jardín o piscina.

El grupo de variables de orientación (norte, sur, este y oeste), identifican si la fachada de la vivienda recae o no en dicha orientación, existiendo la posibilidad de tener varias orientaciones. En este caso, un inmueble puede tener una o más orientaciones, por lo que no hay una de referencia u omitida. Por último, para cuantificar las diferencias que existen a lo largo del territorio, se han definido nueve variables que determinan la ubicación geográfica, estableciéndose para ello las nueve comarcas de la provincia alicantina.

\subsection{Método hedónico de precios}

Con el fin identificar si existe relación entre las características que presentan las viviendas y los precios, así como cuantificar su impacto, se utiliza el análisis de regresión para estimar un modelo hedónico, que permite controlar la heterogeneidad de los precios al introducir las características de las viviendas. De este modo, la estimación del modelo hedónico permite obtener los precios implícitos de las características que presentan las viviendas y evaluar su impacto en el precio (3). Los precios implícitos, derivados de la percepción de los propietarios, pueden cambiar en el tiempo y por ello también los resultados $(11,3)$.

Como apuntan Sirmans et al. (1), los precios implícitos obtenidos para cada característica probablemente no serán los mismos para todos los rangos de precios, por ello, es frecuente que los modelos de precios hedónicos se estimen con formas logarítmicas. De este modo, las estimaciones de los coeficientes son una medida de la elasticidad, permitiendo calcular la variación porcentual en el precio ante un cambio de una unidad en la variable independiente. Siguiendo esta 
línea de especificación de los modelos, en este trabajo se ha tomado el logaritmo neperiano del precio de venta. La expresión semi-logarítmica de la función hedónica utilizada es la siguiente, donde la variable dependiente se expresa en logaritmo, mientras que las independientes no lo están:

$$
\ln \left(P_{i}\right)=\alpha+\sum_{j=1}^{n} \beta_{j} X_{i j}+\sum_{k=1}^{m} \gamma_{k} D_{i k}+\varepsilon_{i}
$$

donde:

- $\ln \left(P_{i}\right)$ es el logaritmo neperiano del precio de venta publicitado para la vivienda " $i$ ".

- $\alpha$ es el componente fijo, no depende del mercado.

- $\beta_{j}$ es el parámetro a estimar relacionado con la característica " $j$ ".

- $X_{i j}$ es la variable continua que recoge la característica "j" de la observación " $\imath$ ".

- $\gamma_{k}$ es el parámetro a estimar relacionado con la característica " $k$ ".

- $D_{i k}$ es la variable ficticia que recoge la característica " $k$ " de la observación " $i$ ".

- $\varepsilon_{i}$ es el término de error de la observación “i”.

Dada la especificación del modelo, el impacto sobre el precio ante un cambio de o a 1 en una variable ficticia, manteniendo constantes el resto de variables independientes, puede calcularse como sugiere Kennedy (24) mediante la expresión [2]. La estimación del porcentaje de cambio de una variable ficticia se denota como $\hat{p}, \hat{V}(\hat{c})$ es la estimación de la varianza del coeficiente $\hat{c}$ en el modelo MCO calculada como el cuadrado de la desviación estándar del coeficiente, es decir, $\hat{V}(\hat{c})=\widehat{S E^{2}}$.

$$
\hat{p}=100\left[\exp \left(\hat{c}-\frac{1}{2} \hat{V}(\hat{c})\right)-1\right]
$$

\subsection{Estimación de los modelos}

La función mostrada en la ecuación [1] se ha utilizado para realizar varias estimaciones. Primero considerando los datos de todas las comarcas y discriminando la situación de la vivienda al introducir una variable ficticia de pertenencia a la comarca, mostrando los resultados en la Tabla 4. En una segunda etapa, se realiza una estimación para cada una de las comarcas alicantinas, habiéndose estimado nueve modelos, cuyos resultados se muestran en la Tabla 5. De este modo, ambas tablas muestran un total de diez estimaciones del modelo, todas ellas realizadas por MCO.

La segmentación atendiendo a la comarca en la que se ubica la vivienda, permite discriminar geográficamente la incidencia que tienen las características que muestran las observaciones, en el precio, y así poder evaluar y comparar el efecto estimado. La geografía alicantina, configurada con zonas de interior y zonas costeras, favorece la existencia de una dualidad, en la que aparece un importante mercado de viviendas, principalmente en las zonas costeras. Cómo interactúan en los precios de venta las diversas características que tienen las viviendas y cómo son valoradas estas cualidades en función de la ubicación de las viviendas, son cuestiones que se quieren abordar en este trabajo.
Como se ha mostrado en la Tabla 2, en promedio existe diversidad entre los precios de las viviendas situadas en las distintas comarcas, sin embargo, no es directamente observable el precio implícito de cada una de las características observadas. El cálculo de estos valores permitirá comprender cómo se valora cada una de las características en función de la ubicación de las viviendas. En este sentido, existen evidencias de que los compradores de viviendas de mayor precio valoran ciertas características de la vivienda, como la superficie o el número de cuartos de baño, de forma diferente a como lo hacen los compradores de viviendas de menor precio (7). La estructura de preferencias de todos los propietarios no es idéntica y los usuarios de viviendas de gama baja y gama alta no solamente se diferencian en las restricciones de ingresos a las que se enfrentan, sino que además, el grado de satisfacción que les proporcionan las características de la vivienda puede ser diferente (7).

\begin{tabular}{|c|c|c|}
\hline & $\begin{array}{c}\text { Var. } \\
\text { independientes }\end{array}$ & $\begin{array}{c}\text { Beta no estand. } \\
\text { (error est.) } \\
\text { [beta estandarizado] }\end{array}$ \\
\hline & (Constante) & $10,346^{* * *}(0,015)$ \\
\hline \multirow{4}{*}{ Tipología } & piso & referencia \\
\hline & atico & $0,105^{* * *}(0,012)[0,040]$ \\
\hline & duplex & $0,078 * * *(0,016)[0,022]$ \\
\hline & estudio & $-0,341^{* * *}(0,029)[-0,055]$ \\
\hline \multirow{7}{*}{$\begin{array}{l}\text { Características } \\
\text { interiores }\end{array}$} & num_baños & $0,288 * * *(0,007)[0,257]$ \\
\hline & num_dormit & $-0,047^{* * *}(0,005)[-0,065]$ \\
\hline & m2constr & $0,005^{* * *}(0,0001)[0,284]$ \\
\hline & terraza & $0,073^{* * *}(0,006)[0,058]$ \\
\hline & aire_acond & $0,084^{* * *}(0,006)[0,065]$ \\
\hline & armarios & $0,028 * * *(0,007)[0,022]$ \\
\hline & fachada_int & $-0,083^{* * *}(0,015)[-0,025]$ \\
\hline \multirow{5}{*}{$\begin{array}{l}\text { Características } \\
\text { exteriores }\end{array}$} & ascensor & $0,275^{* * *}(0,007)[0,199]$ \\
\hline & jardin & $0,055^{* * *}(0,008)[0,037]$ \\
\hline & piscina & $0,218 * * *(0,008)[0,167]$ \\
\hline & plaza_garaje & $0,091^{* * *}(0,007)[0,068]$ \\
\hline & trastero & $0,036^{* * *}(0,007)[0,024]$ \\
\hline \multirow{4}{*}{ Orientación } & norte & $-0,027^{* *}(0,008)[-0,016]$ \\
\hline & sur & $0,060^{* * *}(0,007)[0,047]$ \\
\hline & este & $0,050^{* * *}(0,007)[0,040]$ \\
\hline & oeste & $-0,016^{*}(0,008)[-0,010]$ \\
\hline \multirow{9}{*}{ Ubicación } & Alicante & referencia \\
\hline & Marina_Baja & $0,168 * * *(0,010)[0,089]$ \\
\hline & Marina_Alta & $0,098^{* * *}(0,009)[0,053]$ \\
\hline & Bajo_Vinalopo & $-0,077^{* * *}(0,009)[-0,041]$ \\
\hline & Bajo_Segura & $-0,102^{* * *}(0,008)[-0,066]$ \\
\hline & Medio_Vinalopo & $-0,466^{* * *}(0,016)[-0,132]$ \\
\hline & Alcoy & $-0,455^{* * *}(0,018)[-0,116]$ \\
\hline & Condado & $-0,347^{* * *}(0,052)[-0,030]$ \\
\hline & Alto_Vinalopo & $-0,390^{* * *}(0,029)[-0,060]$ \\
\hline & $R^{2}$ & 0,611 \\
\hline & $R^{2}$ ajustado & 0,611 \\
\hline & Error estándar & 0,392 \\
\hline & $F$ & 1150,40 \\
\hline & Sig & $\mathrm{O}, \mathrm{OOOO}$ \\
\hline & $D W$ & 1,907 \\
\hline & $\begin{array}{l}N \text { observaciones } \\
\text { (obs. completas) }\end{array}$ & $\begin{array}{c}57.182 \\
(19.620) \\
\end{array}$ \\
\hline
\end{tabular}

Tabla 4. Resultados de la estimación no segmentada.

Notas: variable dependiente $\ln$ (precio); ${ }^{* * *} p<0,001,{ }^{* *} p<0,01,{ }^{*} p<0,05$; variables no significativas en gris. 
Tabla 5. Resultados de las nueve estimaciones segmentados por comarca.

\begin{tabular}{|c|c|c|c|c|c|c|c|c|c|c|}
\hline \multirow{3}{*}{. } & & \multicolumn{3}{|c|}{ Litoral Norte } & \multicolumn{2}{|c|}{ Litoral Sur } & \multicolumn{4}{|c|}{ Interior } \\
\hline & $\begin{array}{c}\text { Variables } \\
\text { independientes }\end{array}$ & Alicante & $\underset{\text { Baja }}{\text { Marina }}$ & $\begin{array}{c}\text { Marina } \\
\text { Alta }\end{array}$ & \begin{tabular}{|c|} 
Bajo \\
Vinalopó
\end{tabular} & $\begin{array}{c}\text { Bajo } \\
\text { Segura } \\
\end{array}$ & $\begin{array}{c}\text { Medio } \\
\text { Vinalopó }\end{array}$ & Alcoy & Condado & $\begin{array}{c}\text { Alto } \\
\text { Vinalopó } \\
\end{array}$ \\
\hline & Constante & $\begin{array}{c}10,301^{* * * *} \\
(0,023)\end{array}$ & $\begin{array}{c}10,726^{* * * *} \\
(0,036)\end{array}$ & $\begin{array}{c}10,681^{* * * *} \\
(0,036)\end{array}$ & $\begin{array}{c}10,170^{* * * *} \\
(0,034)\end{array}$ & $\begin{array}{c}10,344^{* * * *} \\
(0,031)\end{array}$ & $\begin{array}{c}9,659^{* * * *} \\
(0,122)\end{array}$ & $\begin{array}{c}9,593^{* * * *} \\
(0,103)\end{array}$ & $\begin{array}{l}9,959^{* * * *} \\
(0,220)\end{array}$ & $\begin{array}{c}9,916 * * * * \\
(0,230)\end{array}$ \\
\hline \multirow{4}{*}{ 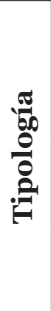 } & piso & \multicolumn{9}{|c|}{ referencia } \\
\hline & atico & $\begin{array}{c}0,068^{* * *} \\
(0,020)\end{array}$ & $\begin{array}{l}0,068^{*} \\
(0,034)\end{array}$ & $\begin{array}{l}0,154^{* * * *} \\
(0,029)\end{array}$ & $\begin{array}{l}0,094^{* * *} \\
(0,036)\end{array}$ & $\begin{array}{l}0,112^{* * * *} \\
(0,026)\end{array}$ & $\begin{array}{c}0,098 \\
(0,122) \\
\end{array}$ & $\begin{array}{c}0,222 \\
(0,117)\end{array}$ & $\begin{array}{c}0,210 \\
(0,203) \\
\end{array}$ & $\begin{array}{l}-0,020 \\
(0,259)\end{array}$ \\
\hline & duplex & $\begin{array}{c}0,011 \\
(0,034)\end{array}$ & $\begin{array}{l}-0,057 \\
(0,053) \\
\end{array}$ & $\begin{array}{l}0,102^{* *} \\
(0,037)\end{array}$ & $\begin{array}{l}0,157^{* * * *} \\
(0,042)\end{array}$ & $\begin{array}{c}0,029 \\
(0,030)\end{array}$ & $\begin{array}{c}0,077 \\
(0,147)\end{array}$ & $\begin{array}{l}-0,034 \\
(0,157) \\
\end{array}$ & $\begin{array}{c}0,059 \\
(0,199)\end{array}$ & constante \\
\hline & estudio & $\begin{array}{c}-0,250^{* * * *} \\
(0,066)\end{array}$ & $\begin{array}{c}-0,412^{* * * *} \\
(0,055)\end{array}$ & $\begin{array}{c}-0,270^{* * *} \\
(0,077)\end{array}$ & $\begin{array}{c}-0,101 \\
(0,084)\end{array}$ & $\begin{array}{c}-0,357^{* * * *} \\
(0,053)\end{array}$ & $\begin{array}{c}0,077 \\
(0,485)\end{array}$ & $\begin{array}{c}0,019 \\
(0,263)\end{array}$ & constante & constante \\
\hline \multirow{7}{*}{ 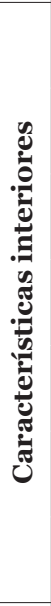 } & num_baños & $\begin{array}{c}0,248^{* * * *} \\
(0,012)\end{array}$ & $\begin{array}{c}0,252^{* * *} \\
(0,018)\end{array}$ & $\begin{array}{c}0,203^{* * * *} \\
(0,017)\end{array}$ & $\begin{array}{c}0,271^{* * * *} \\
(0,016)\end{array}$ & $\begin{array}{c}0,296^{* * * *} \\
(0,015)\end{array}$ & $\begin{array}{l}0,261^{* * * *} \\
(0,054)\end{array}$ & $\begin{array}{c}0,261^{* * * *} \\
(0,058)\end{array}$ & $\begin{array}{l}0,295^{*} \\
(0,120)\end{array}$ & $\begin{array}{l}0,297^{*} \\
(0,117)\end{array}$ \\
\hline & num_dormit & $\begin{array}{c}-0,093^{* * *} \\
(0,007)\end{array}$ & $\begin{array}{l}-0,007 \\
(0,012)\end{array}$ & $\begin{array}{l}-0,022 \\
(0,012)\end{array}$ & $\begin{array}{c}-0,041^{* * *} \\
(0,012)\end{array}$ & $\begin{array}{c}0,011 \\
(0,012) \\
\end{array}$ & $\begin{array}{l}-0,044 \\
(0,035)\end{array}$ & $\begin{array}{c}0,005 \\
(0,033)\end{array}$ & $\begin{array}{c}0,004 \\
(0,073) \\
\end{array}$ & $\begin{array}{c}-0,073 \\
(0,070)\end{array}$ \\
\hline & m2const & $\begin{array}{l}0,007^{* * * *} \\
(0,0002)\end{array}$ & $\begin{array}{l}0,005^{* * *} \\
(0,0003)\end{array}$ & $\begin{array}{l}0,004^{* * *} \\
(0,0003)\end{array}$ & $\begin{array}{l}0,005^{* * *} \\
(0,0003)\end{array}$ & $\begin{array}{l}0,003^{* * * *} \\
(0,0003)\end{array}$ & $\begin{array}{l}0,006^{* * * *} \\
(0,0009)\end{array}$ & $\begin{array}{l}0,007^{* * * *} \\
(0,0008)\end{array}$ & $\begin{array}{c}0,002 \\
(0,0022)\end{array}$ & $\begin{array}{c}0,005^{*} \\
(0,0021)\end{array}$ \\
\hline & terraza & $\begin{array}{l}0,026^{* *} \\
(0,010)\end{array}$ & $\begin{array}{c}0,019 \\
(0,016)\end{array}$ & $\begin{array}{l}0,112^{* * *} \\
(0,018)\end{array}$ & $\begin{array}{c}0,122^{* * * *} \\
(0,016)\end{array}$ & $\begin{array}{c}0,148^{* * * *} \\
(0,015)\end{array}$ & $\begin{array}{c}0,011 \\
(0,058)\end{array}$ & $\begin{array}{c}0,050 \\
(0,057)\end{array}$ & $\begin{array}{c}0,000 \\
(0,119)\end{array}$ & $\begin{array}{c}-0,011 \\
(0,137)\end{array}$ \\
\hline & aire_acond & $\begin{array}{l}0,077^{* * * *} \\
(0,010)\end{array}$ & $\begin{array}{c}0,104^{* * *} \\
(0,016)\end{array}$ & $\begin{array}{c}0,086^{* * *} \\
(0,017)\end{array}$ & $\begin{array}{l}0,077^{* * * *} \\
(0,016)\end{array}$ & $\begin{array}{c}0,051^{* * *} \\
(0,015)\end{array}$ & $\begin{array}{l}0,159^{*} \\
(0,062)\end{array}$ & $\begin{array}{c}0,094 \\
(0,062)\end{array}$ & $\begin{array}{l}-0,018 \\
(0,122)\end{array}$ & $\begin{array}{c}0,165 \\
(0,141)\end{array}$ \\
\hline & armarios & $\begin{array}{c}0,043^{* * *} \\
(0,011)\end{array}$ & $\begin{array}{c}-0,048^{* *} \\
(0,016)\end{array}$ & $\begin{array}{c}0,006 \\
(0,018)\end{array}$ & $\begin{array}{c}0,081^{* * *} \\
(0,016)\end{array}$ & $\begin{array}{l}-0,019 \\
(0,015)\end{array}$ & $\begin{array}{c}0,060 \\
(0,059)\end{array}$ & $\begin{array}{c}0,088 \\
(0,057)\end{array}$ & $\begin{array}{c}0,081 \\
(0,130)\end{array}$ & $\begin{array}{c}0,026 \\
(0,130)\end{array}$ \\
\hline & fachada_int & $\begin{array}{l}-0,073^{*} \\
(0,032)\end{array}$ & $\begin{array}{c}-0,084 \\
(0,046)\end{array}$ & $\begin{array}{l}-0,009 \\
(0,037)\end{array}$ & $\begin{array}{l}-0,034 \\
(0,032)\end{array}$ & $\begin{array}{c}-0,134^{* * *} \\
(0,028)\end{array}$ & $\begin{array}{c}-0,095 \\
(0,089)\end{array}$ & $\begin{array}{l}-0,095 \\
(0,109)\end{array}$ & constante & $\begin{array}{c}0,121 \\
(0,184)\end{array}$ \\
\hline \multirow{5}{*}{ 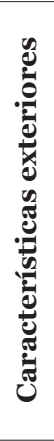 } & ascensor & $\begin{array}{c}0,443^{* * * *} \\
(0,013)\end{array}$ & $\begin{array}{l}0,204^{* * *} \\
(0,02)\end{array}$ & $\begin{array}{l}0,192^{* * * *} \\
(0,018)\end{array}$ & $\begin{array}{c}0,371^{* * * *} \\
(0,016)\end{array}$ & $\begin{array}{l}0,072^{* * *} \\
(0,014)\end{array}$ & $\begin{array}{l}0,431^{* * *} \\
(0,053)\end{array}$ & $\begin{array}{l}0,292^{* * * *} \\
(0,056)\end{array}$ & $\begin{array}{c}0,430^{* * * *} \\
(0,113)\end{array}$ & $\begin{array}{c}0,535^{* * * *} \\
(0,112)\end{array}$ \\
\hline & jardin & $\begin{array}{c}0,017 \\
(0,015)\end{array}$ & $\begin{array}{l}0,038^{*} \\
(0,018)\end{array}$ & $\begin{array}{c}0,072^{* * * *} \\
(0,021)\end{array}$ & $\begin{array}{c}0,000 \\
(0,024)\end{array}$ & $\begin{array}{c}0,134^{* * * *} \\
(0,018)\end{array}$ & $\begin{array}{l}0,004 \\
(0,131)\end{array}$ & $\begin{array}{c}0,148 \\
(0,140)\end{array}$ & $\begin{array}{c}0,167 \\
(0,245)\end{array}$ & $\begin{array}{l}-0,026 \\
(0,358)\end{array}$ \\
\hline & piscina & $\begin{array}{c}0,203^{* * * *} \\
(0,014)\end{array}$ & $\begin{array}{c}0,068^{* * * *} \\
(0,019)\end{array}$ & $\begin{array}{c}0,331^{* * * *} \\
(0,020)\end{array}$ & $\begin{array}{c}0,281^{* * * *} \\
(0,022)\end{array}$ & $\begin{array}{c}0,207^{* * * *} \\
(0,015)\end{array}$ & $\begin{array}{c}0,069 \\
(0,106) \\
\end{array}$ & $\begin{array}{c}0,302 \\
(0,158) \\
\end{array}$ & constante & $\begin{array}{c}-0,015 \\
(0,341) \\
\end{array}$ \\
\hline & plaza_garaje & $\begin{array}{c}0,087^{* * *} \\
(0,012)\end{array}$ & $\begin{array}{c}0,080^{* * * *} \\
(0,017)\end{array}$ & $\begin{array}{c}0,034 \\
(0,018) \\
\end{array}$ & $\begin{array}{c}0,151^{* * * *} \\
(0,018)\end{array}$ & $\begin{array}{c}0,085^{* * *} \\
(0,017)\end{array}$ & $\begin{array}{c}0,134^{*} \\
(0,066)\end{array}$ & $\begin{array}{c}0,159^{*} \\
(0,063)\end{array}$ & $\begin{array}{c}0,175 \\
(0,121)\end{array}$ & $\begin{array}{c}0,139 \\
(0,144) \\
\end{array}$ \\
\hline & trastero & $\begin{array}{c}0,020 \\
(0,012)\end{array}$ & $\begin{array}{c}0,032 \\
(0,020)\end{array}$ & $\begin{array}{c}0,027 \\
(0,019)\end{array}$ & $\begin{array}{l}0,053^{* *} \\
(0,018)\end{array}$ & $\begin{array}{l}0,040^{*} \\
(0,017)\end{array}$ & $\begin{array}{c}0,109 \\
(0,062)\end{array}$ & $\begin{array}{c}0,030 \\
(0,051)\end{array}$ & $\begin{array}{c}0,113 \\
(0,111)\end{array}$ & $\begin{array}{c}0,105 \\
(0,122)\end{array}$ \\
\hline \multirow{4}{*}{ 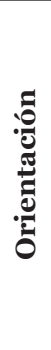 } & norte & $\begin{array}{l}-0,015 \\
(0,014)\end{array}$ & $\begin{array}{c}-0,087^{* * *} \\
(0,029)\end{array}$ & $\begin{array}{c}-0,060^{* *} \\
(0,022)\end{array}$ & $\begin{array}{l}-0,013 \\
(0,019)\end{array}$ & $\begin{array}{l}-0,034 \\
(0,018)\end{array}$ & $\begin{array}{c}0,043 \\
(0,058)\end{array}$ & $\begin{array}{c}0,002 \\
(0,059)\end{array}$ & $\begin{array}{l}-0,033 \\
(0,136)\end{array}$ & $\begin{array}{l}-0,150 \\
(0,136)\end{array}$ \\
\hline & sur & $\begin{array}{c}0,064^{* * *} \\
(0,011)\end{array}$ & $\begin{array}{l}0,039^{*} \\
(0,020)\end{array}$ & $\begin{array}{c}0,033 \\
(0,019)\end{array}$ & $\begin{array}{l}0,037^{*} \\
(0,017)\end{array}$ & $\begin{array}{c}0,084^{* * * *} \\
(0,016)\end{array}$ & $\begin{array}{c}0,070 \\
(0,053)\end{array}$ & $\begin{array}{l}-0,052 \\
(0,057)\end{array}$ & $\begin{array}{c}0,040 \\
(0,137)\end{array}$ & $\begin{array}{l}-0,028 \\
(0,138)\end{array}$ \\
\hline & este & $\begin{array}{c}0,038^{* * *} \\
(0,011)\end{array}$ & $\begin{array}{c}0,024 \\
(0,016)\end{array}$ & $\begin{array}{c}0,025 \\
(0,018) \\
\end{array}$ & $\begin{array}{c}0,048^{* *} \\
(0,017)\end{array}$ & $\begin{array}{c}0,057^{* * * *} \\
(0,016)\end{array}$ & $\begin{array}{c}0,111^{*} \\
(0,052)\end{array}$ & $\begin{array}{c}0,070 \\
(0,054)\end{array}$ & $\begin{array}{c}0,104 \\
(0,126) \\
\end{array}$ & $\begin{array}{c}0,126 \\
(0,123) \\
\end{array}$ \\
\hline & oeste & $\begin{array}{c}-0,011 \\
(0,013) \\
\end{array}$ & $\begin{array}{l}-0,052^{*} \\
(0,021)\end{array}$ & $\begin{array}{c}0,027 \\
(0,022)\end{array}$ & $\begin{array}{c}0,015 \\
(0,018)\end{array}$ & $\begin{array}{l}-0,029 \\
(0,018)\end{array}$ & $\begin{array}{c}0,023 \\
(0,055)\end{array}$ & $\begin{array}{c}0,022 \\
(0,062)\end{array}$ & $\begin{array}{c}0,092 \\
(0,160)\end{array}$ & $\begin{array}{l}-0,039 \\
(0,132)\end{array}$ \\
\hline & $R^{2}$ & 0,633 & 0,509 & 0,512 & 0,638 & 0,443 & 0,626 & 0,669 & 0,710 & 0,629 \\
\hline & $R^{2}$ ajustado & 0,632 & 0,505 & 0,509 & 0,636 & 0,441 & 0,604 & 0,645 & 0,594 & 0,529 \\
\hline & Error estándar & 0,384 & 0,354 & 0,382 & 0,362 & 0,393 & 0,392 & 0,372 & 0,338 & 0,401 \\
\hline & $F$ & 646,44 & 134,13 & 142,57 & 264,17 & 163,70 & 27,78 & 28,19 & 6,12 & 6,29 \\
\hline & Sig & 0,000 & 0,000 & 0,000 & 0,000 & 0,000 & 0,000 & 0,000 & 0,000 & 0,000 \\
\hline & $D W$ & 1,896 & 1,963 & 1,784 & 1,883 & 1,875 & 1,873 & 2,051 & 2,066 & 2,055 \\
\hline & $N$ & 7.128 & 2.462 & 2.486 & 2.866 & 3.924 & 335 & 284 & 57 & 81 \\
\hline
\end{tabular}

Notas: variable dependiente $\ln \left(\right.$ precio); ${ }^{* * *} p<0,001,{ }^{* *} p<0,01,{ }^{*} p<0,05$; variables no significativas en gris; error estándar entre paréntesis; $N$ número de observaciones con datos completos, el total de casos por comarca se indica en la Tabla 2. 
Tabla 6. Descripción de las variables y estadísticos descriptivos.

\begin{tabular}{|c|c|c|c|c|c|c|c|c|}
\hline & Variable & Descripción & $N$ & Min. & Max. & M & $D E$ & $\begin{array}{c}\text { Frec.\% } \\
(=1)\end{array}$ \\
\hline & precio_ln & $\begin{array}{l}\text { Logaritmo neperiano del precio de venta establecido por el } \\
\text { comercializador }(€)\end{array}$ & 57.182 & 8,07 & 13,32 & 11,59 & 0,63 & - \\
\hline \multirow{4}{*}{$\begin{array}{l}\frac{\pi}{60} \\
0 \\
0 \\
0 \\
0\end{array}$} & piso & Dummy para indicar si el inmueble es de tipo piso & 57.182 & 0,0 & 1,0 & 0,90 & 0,30 & 89,7 \\
\hline & atico & Ídem tipo ático & 57.182 & 0,0 & 1,0 & 0,06 & 0,24 & 5,9 \\
\hline & duplex & Ídem tipo dúplex & 57.182 & 0,0 & 1,0 & 0,03 & 0,18 & 3,3 \\
\hline & estudio & Ídem tipo estudio & 57.182 & 0,0 & 1,0 & 0,01 & 0,10 & 1,0 \\
\hline \multirow{7}{*}{ 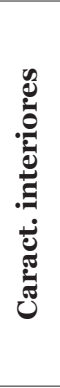 } & num_baños & Número de baños & 57.181 & 0,0 & 4,0 & 1,57 & 0,56 & - \\
\hline & num_dormit & Número de dormitorios & 57.181 & 0,0 & 5,0 & 2,60 & 0,88 & - \\
\hline & m2constr & Metros cuadrados construidos asociados al inmueble $\left(\mathrm{m}^{2}\right)$ & 57.182 & 25,0 & 380,0 & 96,52 & 34,98 & - \\
\hline & terraza & Dummy para identificar la disponibilidad de terraza & 57.182 & 0,0 & 1,0 & 0,49 & 0,50 & 49,3 \\
\hline & aire_acond & Ídem disponibilidad de aire acondicionado & 57.182 & 0,0 & 1,0 & 0,37 & 0,48 & 37,5 \\
\hline & armarios & Ídem disponibilidad de armarios empotrados & 57.182 & 0,0 & 1,0 & 0,47 & 0,50 & 46,9 \\
\hline & fachada_int & $\begin{array}{l}\text { Dummy para identificar si la fachada da a patio interior o a } \\
\text { exterior }\end{array}$ & 37.273 & 0,0 & 1,0 & 0,04 & 0,19 & 3,6 \\
\hline \multirow{5}{*}{ 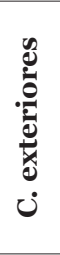 } & ascensor & Dummy para identificar la disponibilidad de ascensor & 54.122 & 0,0 & 1,0 & 0,71 & 0,46 & 70,8 \\
\hline & jardin & Ídem disponibilidad de jardín & 57.182 & 0,0 & 1,0 & 0,24 & 0,43 & 23,9 \\
\hline & piscina & Ídem disponibilidad de piscina & 57.182 & 0,0 & 1,0 & 0,36 & 0,48 & 36,1 \\
\hline & plaza_garaje & Ídem disponibilidad de plaza de garaje & 57.182 & 0,0 & 1,0 & 0,33 & 0,47 & 32,6 \\
\hline & trastero & Ídem disponibilidad de trastero & 57.182 & 0,0 & 1,0 & 0,23 & 0,42 & 22,7 \\
\hline \multirow{4}{*}{ 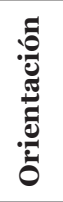 } & norte & Dummy para indicar si tiene o no esta orientación & 24.574 & 0,0 & 1,0 & 0,17 & 0,37 & 16,8 \\
\hline & sur & Ídem anterior & 24.574 & 0,0 & 1,0 & 0,52 & 0,50 & 51,9 \\
\hline & este & Ídem anterior & 24.574 & 0,0 & 1,0 & 0,47 & 0,50 & 46,5 \\
\hline & oeste & Ídem anterior & 24.574 & 0,0 & 1,0 & 0,20 & 0,40 & 19,6 \\
\hline \multirow{9}{*}{ 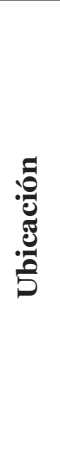 } & Alicante & Dummy para identificar la comarca de Alicante (L'Alacantí) & 57.182 & 0,0 & 1,0 & 0,34 & 0,47 & 34,0 \\
\hline & Marina_Baja & Ídem comarca de la Marina Baja (La Marina Baixa) & 57.182 & 0,0 & 1,0 & 0,13 & 0,33 & 12,6 \\
\hline & Marina_Alta & Ídem comarca de la Marina Alta (La Marina Alta) & 57.182 & 0,0 & 1,0 & 0,13 & 0,34 & 13,2 \\
\hline & Bajo_Vinalopo & Ídem comarca del Bajo Vinalopó (El Baix Vinalopó) & 57.182 & 0,0 & 1,0 & 0,13 & 0,33 & 12,6 \\
\hline & Bajo_Segura & Ídem comarca del Bajo Segura (El Baix Segura) & 57.182 & 0,0 & 1,0 & 0,21 & 0,40 & 20,5 \\
\hline & Medio_Vinal. & Ídem comarca del Medio Vinalopó (El Vinalopó Mitjà) & 57.182 & 0,0 & 1,0 & 0,03 & 0,18 & 3,3 \\
\hline & Alcoy & Ídem comarca de Alcoy (L’Alcoià) & 57.182 & 0,0 & 1,0 & 0,03 & 0,16 & 2,6 \\
\hline & Condado & Ídem comarca del Condado (El Comtat) & 57.182 & 0,0 & 1,0 & 0,00 & 0,05 & 0,3 \\
\hline & Alto_Vinalopo & Ídem comarca del Alto Vinalopó (Alt Vinalopó) & 57.182 & 0,0 & 1,0 & 0,01 & 0,10 & 0,9 \\
\hline
\end{tabular}

Notas: $N$ número de casos; Min. mínimo; Max. máximo; $M$ Media; $D E$ desviación estándar; Frec. Frecuencia (en porcentaje) en la que aparece el valor 1 en base al número de casos $N$.

\section{RESULTADOS}

\subsection{Modelo global de toda la provincia}

La Tabla 4 muestra los resultados obtenidos para la estimación del modelo [1], considerando las observaciones de todas las comarcas y discriminando la situación de la vivienda al introducir una variable ficticia de pertenencia a la comarca. Para interpretar los coeficientes beta de las variables ficticias se ha utilizado la expresión sugerida por Kennedy (24).

En relación con el primero de los grupos de análisis, y atendiendo a la definición de las variables que lo integran (Tabla 3), se puede observar que la variable de referencia es la tipología piso, y con respecto a esta, las viviendas de tipología ático y dúplex tienen un precio superior (11,06\% y 8,10\% respectivamente), mientras que un estudio tiene un precio inferior (28,92\%). (Ver
Tabla A.1, nota: como ejemplo, el porcentaje estimado de cambio para la tipología ático, conforme a la ec. [2], se calcula como $\left.\hat{p}=100 \cdot\left[\exp \left(0,105-1 / 2 \cdot 0,012^{2}\right)-1\right]=11,06 \%\right)$.

En relación a las características interiores, las tres primeras, "num_baños, num_dormit y m2constr" se han definido con variables continuas, mientras que en el resto se han utilizado variables ficticias. Estas tres características interiores forman parte de las veinte características que más aparecen en los modelos de precios hedónicos (1). El impacto que tienen sobre los precios el número de baños, de dormitorios y la superficie construida es diferente. Los resultados obtenidos muestran en media que el incremento de un baño supone un aumento en el precio del $28,8 \%$, y que por cada metro cuadrado de superficie construida adicional, el precio se incrementa en un $0,5 \%$. Por el contrario, el incremento de un dormitorio más, hace caer el precio una media del $4,7 \%$. 
El coeficiente obtenido para la superficie construida (0,5\%), está próximo al o,37\% obtenido por García-Pozo (15) en Málaga, pero lejos del 1-2\% obtenido por Marmolejo-Duarte (17) en Barcelona. Sirmans et al. (1) encuentran que la superficie es una variable que aparece con frecuencia en los modelos hedónicos y que en la mayoría de las ocasiones el signo que presenta es positivo. McGreal y Taltavull (3) también obtienen relaciones positivas entre la superficie y el precio de las viviendas. Aun siendo un porcentaje bajo, el efecto de la escala en que está medida hace muy relevante esta característica, pudiéndose verificar a partir de los coeficientes betas estandarizados. Con respecto al número de baños, Sirmans et al. (1) también encuentran que mayoritariamente el signo obtenido es positivo. Otros autores obtienen coeficientes parecidos, como un $23 \%$ en (16), o con efectos mucho menores, $13 \%$ en (17) o el 12,6\% en (15). En cuanto al número de dormitorios, el signo negativo o la no significatividad del parámetro aparecen con frecuencia (1).

Respecto a las variables ficticias, la disponibilidad de aire acondicionado implica un incremento medio en el precio de un $8,76 \%$, tener terraza un $7,57 \%$, la de armarios empotrados un $2,84 \%$ y la iluminación a través de un patio interior en lugar de a través de una fachada exterior, una reducción del precio del 7,98\%. En relación a la instalación de aire acondicionado Sirmans et al. (1) indican que, en la mayoría de estudios que se ha analizado esta característica, el signo que acompañada al coeficiente es positivo. En relación a la iluminación exterior, Sirmans et al. (1), a pesar de que en su trabajo no incluyen directamente la iluminación exterior a la calle, sí que aporta evidencias de que las características del entorno natural, como las buenas vistas, tienen efectos positivos sobre los precios en la mayoría de los estudios que analizan. García-Pozo (15) estima una reducción del precio del 16,25\% cuando la vivienda tiene escasa iluminación natural.

En cuanto a las características exteriores, todas ellas presentan signo positivo, lo que implica que la presencia de la característica hace que el precio se incremente. El efecto más importante se ha obtenido para la existencia de ascensor, que hace que el precio de la vivienda aumente de media en un $31,65 \%$, seguido de la disponibilidad de piscina con un 24,36 . Otros aspectos como disponer de plaza de garaje aumenta el precio de media un 9,52\%, el jardín un $5,65 \%$, y finalmente el trastero un $3,66 \%$. Varios autores $(3,13)$ también encuentran que la existencia de ascensor tiene un impacto positivo importante sobre el precio de venta. El impacto relevante que el modelo asigna a la existencia de urbanización en la edificación, que el modelo captura considerado la existencia de piscina y jardín, ha sido detectado en Pérez-Sánchez (25), para un trabajo realizado en el mercado alicantino de vivienda de nueva construcción. Sirmans et al. (1) muestran como la existencia de piscina o plaza de aparcamiento están dentro de las veinte características que más aparecen en los modelos hedónicos, no habiendo aparecido en ninguno de los que analizan con signo negativo.

En relación con la orientación, se ha obtenido un impacto positivo sobre el precio para aquellas edificaciones con orientación sur y este $(6,18 \%$ y $5,12 \%$ respectivamente), mientras que el impacto ha sido de signo contrario para las orientaciones norte y oeste $(-2,67 \%$ y $-1,59 \%$ respectivamente). No se aprecian problemas de colinealidad en estas variables (ver VIF en Tabla A.1). Otros trabajos como $(3,13)$ también encuentran impactos significativos de la orientación en los precios, que la consideran especialmente relevante en el caso de Alicante y Castellón.
Respecto a la ubicación, y en referencia a la comarca de Alicante, se puede observar como son las viviendas situadas en las comarcas litorales del norte (Marina Baja y Marina Alta), las que tienen unos precios superiores, mientras que las situadas en el litoral sur (Bajo Vinalopó y Bajo Segura) y el resto de comarcas del interior, tienen unos precios inferiores. En referencia al impacto estimado, en la zona norte los precios de las vivienda situadas en la Marina Baja son en media un $18,29 \%$ superiores a los de Alicante, mientras que en la Marina Alta alcanza el 10,29\%. Las comarcas costeras del sur de la provincia (Bajo Vinalopó y Bajo Segura), tienen precios inferiores a los de Alicante un 7,41\% y un 9,70\% respectivamente. En el caso de los precios de las viviendas situadas en las comarcas interiores, las diferencias son superiores, encontrando precios entre un 29,41\% menor en el caso del Condado o hasta un 37,26\% en el Medio Vinalopó.

Para estimar la importancia relativa de cada variable en el modelo de regresión se utiliza un método desarrollado por Lindeman et al. (26), que permite descomponer la variabilidad explicada de cada variable independiente. Se utiliza el averaged over orderings method (métrica $\mathrm{lmg}$ ) incluido en el paquete "relaimpo" (versión 2.2-3) de R, desarrollado por Grömping (27). Éste método descompone el $R^{2}$ en contribuciones no negativas que suman el total de $R^{2}$. Como desventaja de este método, indicar que es computacionalmente prohibitivo a medida que aumenta el número de predictores. Esto es debido a que calcula la contribución de cada predictor en todas las formas posibles de entrada al modelo de regresión, realizando el promedio de esas contribuciones, de esta manera se crean tantas estimaciones del modelo de regresión como permutaciones sin repetición sean posibles.

Como se describe en la Figura 2.a, el modelo no segmentado explica un porcentaje de varianza del precio del $61,1 \%$, siendo las características interiores (32,68\%) y las exteriores $(18,11 \%)$ las que explican una mayor varianza. En conjunto, las características de la vivienda explican el 53,89\% de la varianza, mientras que la ubicación sólo explica el 7,21\%. La varianza no explicada del precio $(38,90 \%)$ se debe a diversos factores, como la omisión en el modelo de otras variables explicativas, así como a la variabilidad y heterogeneidad de la muestra (algo habitual en este tipo de datos). Las variables con mayor importancia relativa en el modelo son, ordenadas de mayor a menor (Figura 2.b): la superficie construida, el número de baños, la disponibilidad de ascensor, piscina y plaza de garaje.

\subsection{Modelos segmentados por comarcas}

La Tabla 5 muestra los resultados obtenidos al segmentar los datos en función de la comarca en la que se ubica el inmueble. La información que aparece está organizada siguiendo el mismo criterio seguido en la Tabla 4. Se evidencia que la segmentación de la base de datos afecta fundamentalmente a las comarcas del interior, en cuyas estimaciones se han obtenido un elevado número de variables no significativas al disponer de menos observaciones.

En relación con la tipología (Figura 3.a), el mayor impacto positivo se produce en la comarca de la Marina Alta en la que un ático tiene un precio superior a un piso en un $16,64 \%$. Con respecto a la tipología dúplex solamente en los casos de la Marina-Alta y el Bajo Vinalopó la variable es significativa. La tipología estudio ha sido significativa en cuatro comarcas, con descuentos entre el 22 y el $34 \%$. 


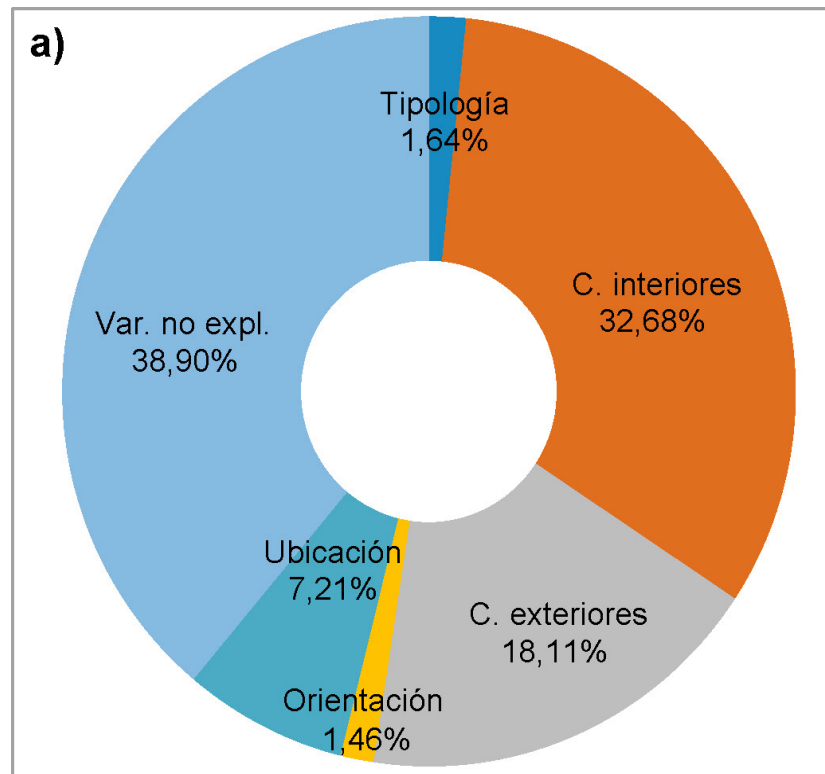

b) Importancia relativa estimada (\%)

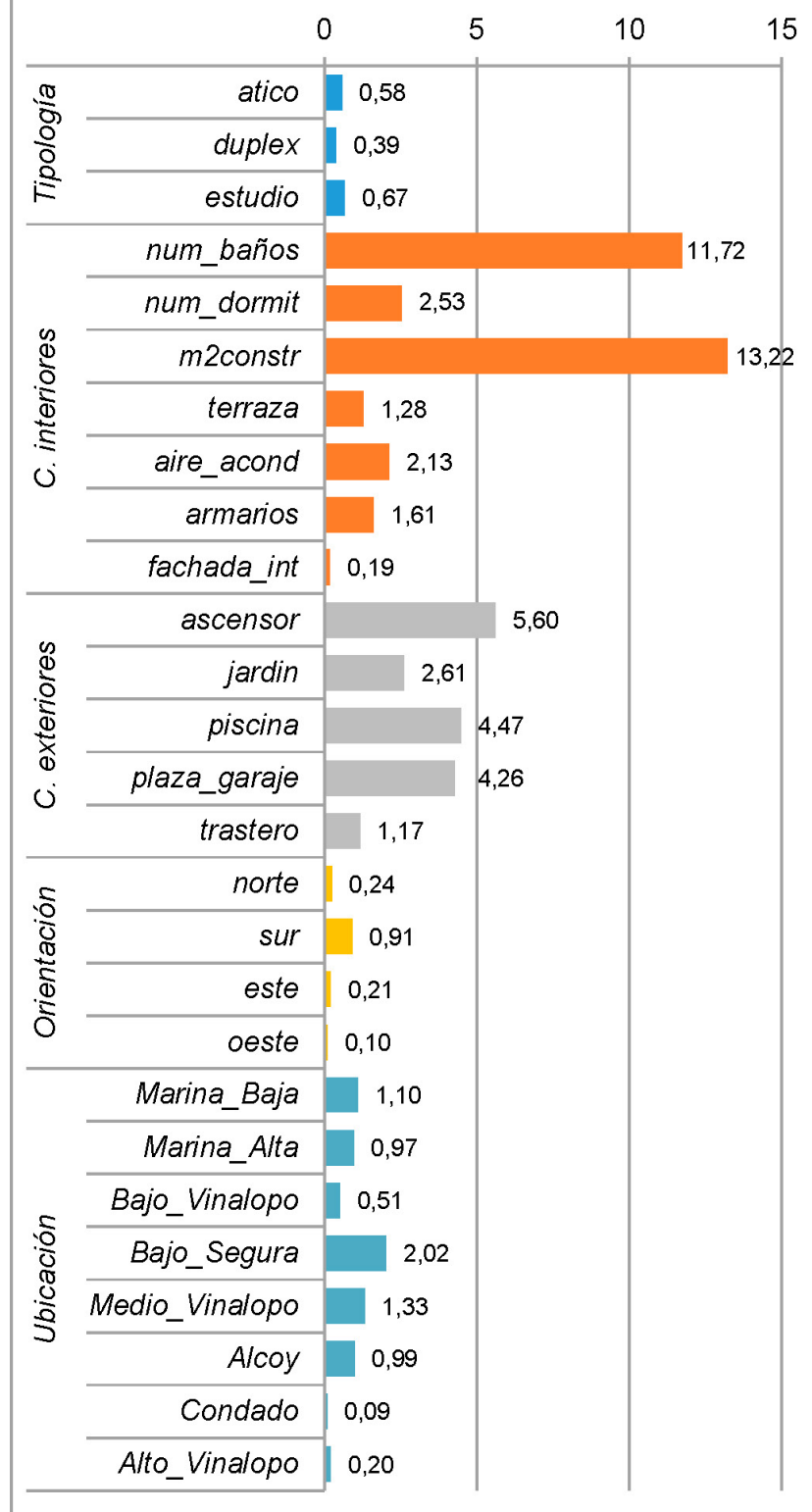

Figura 2. a) Descomposición de la varianza explicada $\left(R^{2}\right)$ por agrupación. b) Importancia relativa para cada variable. $(N=19.620)$.
Con respecto a las características interiores (Figura 3.b), el número de baños es la única significativa en todas las comarcas, siendo su signo positivo y el efecto similar en todas ellas (entre el 22 y el 34\% por cada baño adicional). Algo similar ocurre con la superficie construida, a pesar de que no es significativa en la comarca del Condado, en el resto de comarcas presenta signo positivo, entre un 0,4 y 0,7\% por cada metro cuadrado adicional. La disponibilidad de aire acondicionado y terraza son otras de las características significativas en varias de las comarcas que muestran impactos en los precios positivos, siendo más relevantes en zonas de litoral y clima más cálido.

En relación a las características exteriores (Figura 3.c), en la mayoría de las comarcas del litoral son significativas la existencia de ascensor, piscina o plaza de garaje. Estas características muestran diferentes impactos sobre los precios en función de la comarca en la que se sitúa la vivienda. Por ejemplo, la existencia de ascensor, evidencia una mayor influencia y variabilidad sobre los precios, con diferencias importantes entre las distintas comarcas. Es en la comarca del Alto Vinalopó en la que se ha obtenido el impacto más importante (69,62\%), mientras que el efecto menos relevante se ha obtenido para el Bajo Segura (7,43\%). Respecto a la piscina, los resultados muestran un impacto sobre los precios de entre el 7 y $39 \%$ en el caso del litoral

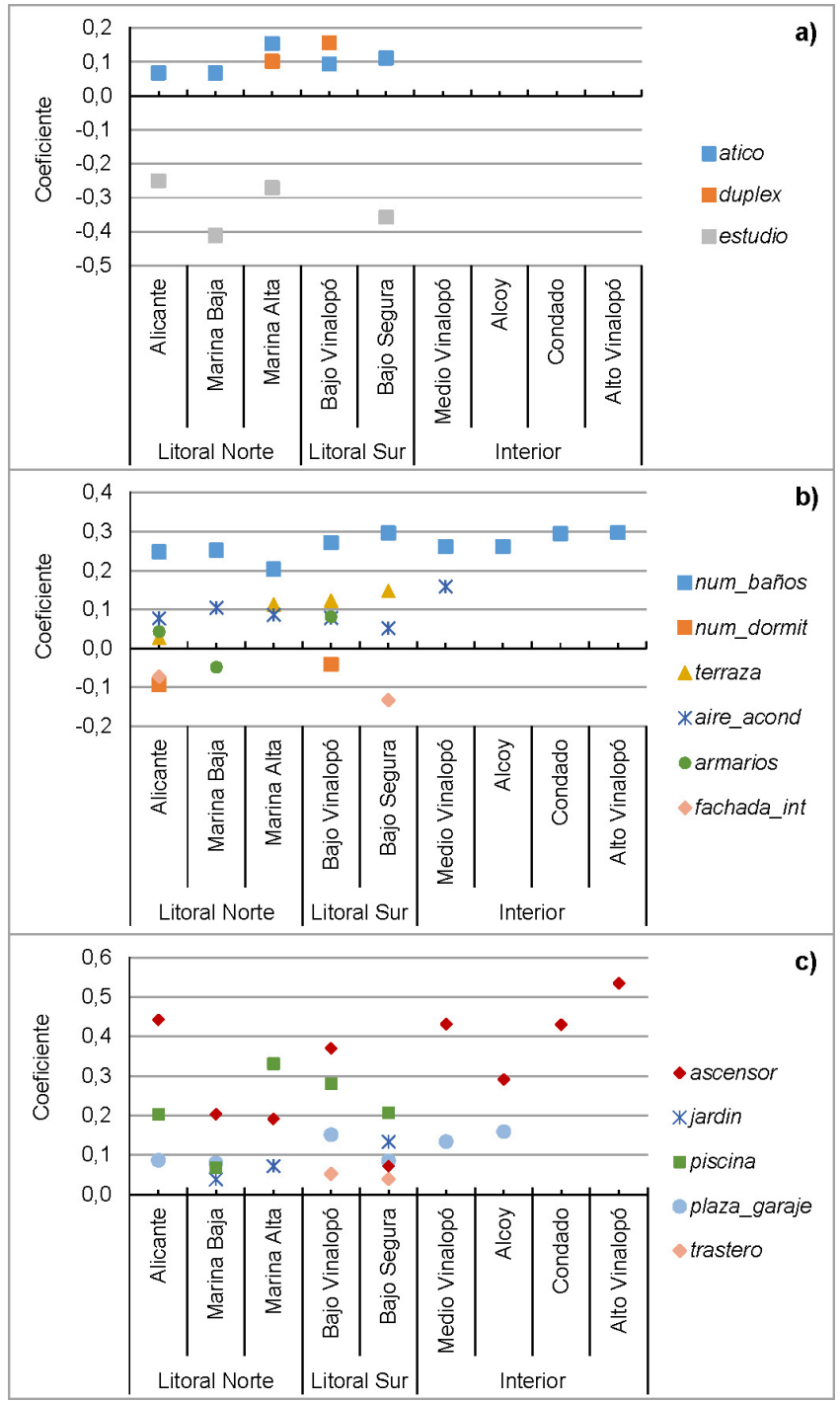

Figura 3. Coeficientes beta por comarca. a) Tipología de vivienda. b) Características interiores. c) Características exteriores. 
norte, entre un 23 y $32 \%$ en el litoral sur. En relación a la plaza de garaje, en la zona del litoral norte, la influencia sobre los precios oscila entre el 8 y $9 \%$, en el litoral sur entre el 9 y $16 \%$.

En referencia a la orientación, y cuando las variables son significativas, los resultados muestran que las orientaciones sur y este tienen un impacto positivo sobre los precios de las viviendas, con un efecto que varía entre el 3 y el 11\%.

\section{DISCUSIÓN}

Como se ha ido comentando a lo largo de los resultados, los coeficientes estimados por el modelo en los análisis realizados, muestran signos acordes con la literatura y permiten cuantificar el impacto de las características que presentan las viviendas en sus precios. Atendiendo a la tipología de vivienda analizada, es el tipo ático el que muestra un precio de venta superior, respecto a la tipología piso, siendo el efecto más alto en la Marina Alta. La configuración urbanística de las ciudades hace que este tipo de viviendas sea relativamente escaso, además es frecuente que muestren características diferenciadoras con respecto a otras viviendas (ocupar la última planta de los edificios, tener unas mayores superficies, mejores vistas, o importantes terrazas), que el mercado valora y el modelo ha sido capaz de capturar.

En relación a las características interiores, el modelo asigna el impacto más relevante a la superficie construida y al número de baños. Por comarcas, los resultados obtenidos van en la misma dirección, siendo en el Bajo Segura y Alto Vinalopó donde el número de baños tiene el impacto más alto. La superficie construida es más relevante en las comarcas de Alicante y Alcoy y menos en el Bajo Segura. En relación a otras características interiores de la vivienda, como son la existencia de terraza o aire acondicionado, los modelos están capturando un incremento en el precio de venta, aunque no en todas las comarcas por igual, siendo no significativo en algunas de ellas.

Con respeto a las características exteriores, el impacto de todas ellas sobre el precio de venta es positivo, tanto en la estimación global como por comarcas, siendo más importantes los efectos estimados por la existencia de ascensor, piscina y plaza de garaje. Las otras dos cualidades observadas, dentro de esta categoría, tienen un menor efecto sobre el precio. El resultado obtenido muestra que la comarca con menor relevancia a tener ascensor es la del Bajo Segura, seguramente por la menor altura de sus edificios, mientras que la existencia de piscina es más relevante en las comarcas costeras. Disponer de plaza de garaje eleva el precio de venta por encima del $10 \%$, con variaciones sustanciales entre comarcas. La existencia de jardín tiene un impacto sobre los precios algo inferior (entorno al 6\%) y finalmente la existencia de trastero es la característica a la que el modelo asigna la menor influencia sobre los precios. Con todo ello, se aprecia que las preferencias de los usuarios cambian según la comarca.

Con relación a la orientación, los parámetros estimados por los modelos muestran como las orientaciones sur y este son las mejor valoradas, mientras que las viviendas orientadas al norte $o$ al oeste muestran precios más bajos.

En relación con la ubicación, y respecto a la comarca de Alicante, los resultados muestran una segmentación de precios entre la zona costera y la zona interior. La zona litoral del norte de la provincia de Alicante (Marina Alta y Marina Baja) es la zona en la que los precios de venta son superiores, entorno al 10-18\%. La zona litoral sur, (Bajo Vinalopó y Bajo Segura), muestra unos precios inferiores a los de la comarca de Alicante (7\%). Sin embargo, los resultados obtenidos para las comarcas del interior, muestran unos precios de entre un 29 y un 37\% menor que las situadas en la comarca de Alicante. Los resultados asignan un importante papel en la definición de precios al litoral costero, habiéndose obtenido unas diferencias relevantes y significativas entre las comarcas costeras y las del interior.

\section{CONCLUSIONES}

Este estudio pretende analizar y cuantificar la influencia que tienen en el precio de venta determinadas características de viviendas multifamiliares de segunda mano situadas en la provincia de Alicante. Para ello se ha estimado en diez ocasiones un modelo hedónico por mínimos cuadrados ordinarios, utilizando 29 variables independientes y una muestra de más de 57.000 inmuebles. La primera estimación corresponde a un modelo global que agrupa todas las observaciones de la muestra y permite identificar la influencia en el precio según la localización (por comarcas). El modelo global ha sido capaz de detectar las diferencias territoriales que existen en el precio de venta (por comarcas), además de estimar el valor implícito de las características de los inmuebles. Después, se realizan nueve estimaciones independientes, segmentando la muestra para cada comarca, identificando las variables que son más representativas para cada mercado local.

Los resultados obtenidos muestran la gran relevancia de las características intrínsecas de las viviendas para determinar el precio de venta, como apuntan Sirmans et al. (1), donde identifican las características principales que han sido utilizadas en estos modelos de precios hedónicos. Las características de ubicación también muestran que existen dos mercados diferenciados en la provincia de Alicante, entre la zona de costa y la de interior.

A modo de síntesis, se puede indicar que los resultados muestran que, de las cuatro tipologías de vivienda analizadas, son las de tipo ático las que tienen un mayor precio. Se ha observado que las características internas con un mayor impacto sobre los precios son la superficie construida y el número de baños, mientras que otras características externas como la disponibilidad de ascensor, piscina y/o plaza de garaje implican un efecto importante sobre los precios. En relación a la orientación, son más valoradas las viviendas que se orientan al sur y al este, por el contrario, las viviendas con orientaciones norte u oeste tienen una reducción en su precio. Con respecto a la situación, y tomando como referencia la comarca de Alicante, la zona litoral costera del norte de la provincia, ocupada por las Marinas Alta y Baja, son las zonas donde hay un mayor precio de venta, mientras que las comarcas del litoral sur y del interior muestran precios de venta inferiores. Las diferencias entre los precios son significativas, y relevantes si se comparan las comarcas costeras con las del interior.

Las estimaciones realizadas por comarcas, evidencian que las preferencias de los usuarios cambian según éstas. Las comarcas costeras cuentan con un mayor número de variables significativas. Al igual que ocurre en la estimación global, las características más relevantes y estadísticamente significativas en casi todas las comarcas son: la superficie construida, el número de baños y la disponibilidad de ascensor. 


\section{REFERENCIAS}

(1) Sirmans, G.S., Macpherson, D.A. y Zietz, E.N. (2005). The composition of Hedonic Pricing Models. Journal of Real Estate Literature, 13(1): 3-43. Recuperado de http://aresjournals.org/doi/abs/10.5555/reli.13.1.jo3673877172w0w2

(2) Nicodemo, C. y Raya, J.M. (2012). Change in the distribution of house prices across Spanish cities. Regional Science and Urban Economics, 42(4): 739-748. https://doi.org/10.1016/j.regsciurbeco.2012.05.003

(3) McGreal, S. y Taltavull, P. (2013). Implicit house prices: variation over time and space in Spain. Urban Studies, 50(10): 2024-2043. https://doi.org/10.1177/0042098012471978

(4) Taltavull, P. (2003). Determinants of housing prices in Spanish cities. Journal of Property Investment \& Finance, 21(2): 109-135. https://doi.org/10.1108/14635780310469102

(5) Bengochea-Morancho, A. (2003). A hedonic valuation of urban green areas. Landscape and Urban Planning, 66(1): 3541. https://doi.org/10.1016/So169-2046(03)00093-8

(6) Chasco-Yrigoyen, C. y Sánchez-Reyes, B. (2012). Externalidades ambientales y precio de la vivienda en Madrid: un análisis con regresión cuantílica espacial. Revista Galega de Economía, 21(2): 277-296. Recuperado de http://hdl.handle. net/10347/19009

(7) Zietz, J., Zietz, E.N. y Sirmans, G.S. (2008). Determinants of house prices: a Quantile Regression approach. The Journal of Real Estate Finance and Economics, 37(4): 317-333. https://doi.org/10.1007/s11146-007-9053-7

(8) Court, A.T. (1939). Hedonic price indexes with automotive examples. In The dinamics of automovile demand (pp. 99117). New York: General Motors Corporation.

(9) Ridker, R.G. y Henning, J.A. (1967). The Determinants of Residential Property Values with Special Reference to Air Pollution. The Review of Economics and Statistics, 49(2): 246-257. https://doi.org/10.2307/1928231

(10) Núñez-Tabales, J.M. (2007). Mercados inmobiliarios: modelización de los precios (Tesis doctoral). Córdoba: Universidad de Córdoba. Recuperado de http://hdl.handle.net/10396/428

(11) Rosen, S. (1974). Hedonic prices and implicit markets: product differentiation in pure competition. Journal of Political Economy, 82(1): 34-55. https://doi.org/10.1086/260169

(12) García-Pozo, A. (2007). Una aproximación a la aplicación de la metodología hedónica: Especial referencia al caso del mercado de la vivienda. Cuadernos de Ciencias Económicas y Empresariales, 53: 53-81. Recuperado de http://cuadernos.uma.es/pdfs/pdf644.pdf

(13) Taltavull, P. y McGreal, S. (2009). Measuring price expectations: Evidence from the Spanish housing market. Journal of European Real Estate Research, 2(2): 186-209. https://doi.org/10.1108/17539260910978481

(14) Baudry, M., Guengant, A., Larribeau, S. y Leprince, M. (2009). Formation des prix immobiliers et consentements à payer pour une amélioration de l'environnement urbain : l'exemple rennais. Revue d'Économie Régionale \& Urbaine, 2(2): 369-411. https://doi.org/10.3917/reru.092.0369

(15) García-Pozo, A. (2008). Determinantes del precio de la vivienda usada en Málaga una aplicación de la metodología hedónica. Revista de estudios regionales, 82: 135-158. Recuperado de http://www.revistaestudiosregionales.com/documentos/articulos/pdf1043.pdf

(16) Din, A., Hoesli, M. y Bender, A. (2001). Environmental Variables and Real Estate Prices. Urban Studies, 38(11): 19892000. https://doi.org/10.1080/00420980120080899

(17) Marmolejo-Duarte, C. (2016). La incidencia de la calificación energética sobre los valores residenciales: un análisis para el mercado plurifamiliar en Barcelona. Informes de la Construcción, 68(543): e156. http://doi.org/10.3989/ic.16.053

(18) de Ayala, A., Galarraga, I. y Spadaro, J.V. (2016). The price of energy efficiency in the Spanish housing market. Energy Policy, 94: 16-24. https://doi.org/10.1016/j.enpol.2016.03.032

(19) Keskin, B. y Watkins, C. (2017). Defining spatial housing submarkets: Exploring the case for expert delineated boundaries. Urban Studies, 54(6): 1446-1462. https://doi.org/10.1177/0042098015620351

(20) Lama-Santos, F.A.d. (2017). Determinación de las cualidades de valor en la valoración de bienes inmuebles. La influencia del nivel socioeconómico en la valoración de la vivienda (Tesis doctoral). Universidad Politécnica de Valencia. https://doi.org/10.4995/Thesis/10251/90526

(21) Hite, D., Chern, W., Hitzhusen, F. y Randall, A. (2001). Property-Value Impacts of an Environmental Disamenity: The Case of Landfills. The Journal of Real Estate Finance and Economics, 22(2): 185-202. https://doi.org/10.1023/A:1007839413324

(22) Agnew, K. y Lyons, R.C. (2018). The impact of employment on housing prices: Detailed evidence from FDI in Ireland. Regional Science and Urban Economics, 70: 174-189. https://doi.org/10.1016/j.regsciurbeco.2018.01.011

(23) Ogwang, T. y Wang, B. (2003). A Hedonic Price Function for a Northern BC Community. Social Indicators Research, 61(3): 285-296. https://doi.org/10.1023/A:1021905518866

(24) Kennedy, P.E. (1981). Estimation with correctly interpreted dummy variables in semilogarithmic equations. The American Economic Review, 71(4): 801. Recuperado de http://www.jstor.org/stable/1806207

(25) Pérez-Sánchez, V.R. (2015). Costes de edificación y precios de las viviendas. Evidencia en la provincia de Alicante (Tesis doctoral). Alicante: Universidad de Alicante. Recuperado de http://hdl.handle.net/10045/46127

(26) Lindeman, R.H., Merenda, P.F. y Gold, R.Z. (1980). Introduction to bivariate and multivariate analysis. Glenview, IL: Scott, Foresman and Company.

(27) Grömping, U. (2006). Relative Importance for Linear Regression. In R: The package relaimpo. Journal of Statistical Software, 17(1): 27. https://doi.org/10.18637/jss.v017.io1 


\section{A. ANEXO}

La Tabla A.1, amplía y complementa la Tabla 4 del documento principal, recopila los datos detallados de los regresores, informando sobre los coeficientes betas no estandarizados con sus términos de error estándar, los betas estandarizados, prueba $t$ y su significación estadística, intervalos de confianza al 95\% de cada coeficiente beta, y los estadísticos de colinealidad (Tolerancia y VIF). En la última columna del modelo se incluye la estimación del porcentaje de cambio de las variables ficticias, calculada como sugiere Kennedy (24) mediante la expresión [2].

Tabla A.1. Resultados de la estimación no segmentada para toda la provincia de Alicante.

\begin{tabular}{|c|c|c|c|c|c|c|c|c|c|c|c|}
\hline & \multirow[b]{2}{*}{$\begin{array}{c}\text { Variables } \\
\text { independientes }\end{array}$} & \multicolumn{2}{|c|}{$\begin{array}{l}\text { Coeficientes no } \\
\text { estandarizados }\end{array}$} & \multirow{2}{*}{$\begin{array}{c}\begin{array}{c}\text { Coef. } \\
\text { estandariz. }\end{array} \\
\text { Beta }\end{array}$} & \multirow[b]{2}{*}{$t$} & \multirow[b]{2}{*}{ Sig. } & \multicolumn{2}{|c|}{$\begin{array}{l}95 \% \text { intervalo de } \\
\text { confianza para B }\end{array}$} & \multicolumn{2}{|c|}{$\begin{array}{l}\text { Estadísticas de } \\
\text { colinealidad }\end{array}$} & \multirow{2}{*}{$\begin{array}{c}\text { Coef. } \\
\text { beta } \\
\text { corregido } \\
(\%)\end{array}$} \\
\hline & & $\boldsymbol{B}$ & $\begin{array}{l}\text { Error } \\
\text { estándar }\end{array}$ & & & & $\begin{array}{c}\text { Límite } \\
\text { inferior }\end{array}$ & $\begin{array}{c}\text { Límite } \\
\text { superior }\end{array}$ & Tolerancia & VIF & \\
\hline & (Constante) & 10,346 & 0,015 & & 697,221 & 0,000 & 10,317 & 10,375 & & & - \\
\hline \multirow{4}{*}{ 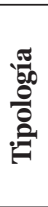 } & piso & \multicolumn{9}{|c|}{ referencia } & \\
\hline & atico & 0,105 & 0,012 & 0,040 & 8,608 & 0,000 & 0,081 & 0,129 & 0,933 & 1,072 & 11,06 \\
\hline & duplex & 0,078 & 0,016 & 0,022 & 4,736 & 0,000 & 0,046 & 0,110 & 0,903 & 1,107 & 8,10 \\
\hline & estudio & $-0,341$ & 0,029 & $-0,055$ & $-11,781$ & 0,000 & $-0,398$ & $-0,285$ & 0,891 & 1,122 & $-28,92$ \\
\hline \multirow{7}{*}{ 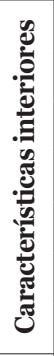 } & num_baños & 0,288 & 0,007 & 0,257 & 43,273 & 0,000 & 0,275 & 0,301 & 0,556 & 1,799 & - \\
\hline & num_dormit & $-0,047$ & 0,005 & $-0,065$ & $-10,016$ & 0,000 & $-0,056$ & $-0,038$ & 0,465 & 2,150 & - \\
\hline & m2constr & 0,005 & 0,0001 & 0,284 & 44,537 & 0,000 & 0,005 & 0,005 & 0,485 & 2,061 & - \\
\hline & terraza & 0,073 & 0,006 & 0,058 & 11,400 & 0,000 & 0,060 & 0,086 & 0,757 & 1,321 & 7,57 \\
\hline & aire_acond & 0,084 & 0,006 & 0,065 & 12,948 & 0,000 & 0,071 & 0,096 & 0,793 & 1,262 & 8,76 \\
\hline & armarios & 0,028 & 0,007 & 0,022 & 4,334 & 0,000 & 0,015 & 0,041 & 0,737 & 1,357 & 2,84 \\
\hline & fachada_int & $-0,083$ & 0,015 & $-0,025$ & $-5,510$ & 0,000 & $-0,112$ & $-0,053$ & 0,984 & 1,016 & $-7,98$ \\
\hline \multirow{5}{*}{ 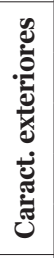 } & ascensor & 0,275 & 0,007 & 0,199 & 40,140 & 0,000 & 0,262 & 0,289 & 0,798 & 1,253 & 31,65 \\
\hline & jardin & 0,055 & 0,008 & 0,037 & 6,493 & 0,000 & 0,038 & 0,072 & 0,594 & 1,685 & 5,65 \\
\hline & piscina & 0,218 & 0,008 & 0,167 & 27,387 & 0,000 & 0,202 & 0,234 & 0,531 & 1,884 & 24,36 \\
\hline & plaza_garaje & 0,091 & 0,007 & 0,068 & 12,861 & 0,000 & 0,077 & 0,104 & 0,711 & 1,407 & 9,52 \\
\hline & trastero & 0,036 & 0,007 & 0,024 & 4,836 & 0,000 & 0,021 & 0,050 & 0,816 & 1,225 & 3,66 \\
\hline \multirow{4}{*}{ 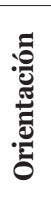 } & norte & $-0,027$ & 0,008 & $-0,016$ & $-3,283$ & 0,001 & $-0,044$ & $-0,011$ & 0,797 & 1,254 & $-2,67$ \\
\hline & sur & 0,060 & 0,007 & 0,047 & 8,610 & 0,000 & 0,046 & 0,073 & 0,647 & 1,545 & 6,18 \\
\hline & este & 0,050 & 0,007 & 0,040 & 7,575 & 0,000 & 0,037 & 0,063 & 0,717 & 1,395 & 5,12 \\
\hline & oeste & $-0,016$ & 0,008 & $-0,010$ & $-2,025$ & 0,043 & $-0,031$ & $-0,001$ & 0,817 & 1,224 & $-1,59$ \\
\hline \multirow{9}{*}{ 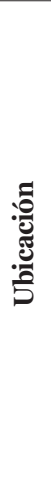 } & Alicante & \multicolumn{9}{|c|}{ referencia } & \\
\hline & Marina_Baja & 0,168 & 0,010 & 0,089 & 17,220 & 0,000 & 0,149 & 0,187 & 0,740 & 1,352 & 18,29 \\
\hline & Marina_Alta & 0,098 & 0,009 & 0,053 & 10,407 & 0,000 & 0,080 & 0,117 & 0,763 & 1,311 & 10,29 \\
\hline & Bajo_Vinalopo & $-0,077$ & 0,009 & $-0,041$ & $-8,270$ & 0,000 & $-0,096$ & $-0,059$ & 0,806 & 1,241 & $-7,41$ \\
\hline & Bajo_Segura & $-0,102$ & 0,008 & $-0,066$ & $-12,233$ & 0,000 & $-0,119$ & $-0,086$ & 0,682 & 1,467 & $-9,70$ \\
\hline & $\begin{array}{l}\text { Medio_Vina- } \\
\text { lopo }\end{array}$ & $-0,466$ & 0,016 & $-0,132$ & $-28,510$ & 0,000 & $-0,498$ & $-0,434$ & 0,912 & 1,097 & $-37,26$ \\
\hline & Alcoy & $-0,455$ & 0,018 & $-0,116$ & $-25,095$ & 0,000 & $-0,490$ & $-0,419$ & 0,927 & 1,078 & $-36,57$ \\
\hline & Condado & $-0,347$ & 0,052 & $-0,030$ & $-6,684$ & 0,000 & $-0,448$ & $-0,245$ & 0,991 & 1,009 & $-29,41$ \\
\hline & Alto_Vinalopo & $-0,390$ & 0,029 & $-0,060$ & $-13,300$ & 0,000 & $-0,447$ & $-0,332$ & 0,970 & 1,031 & $-32,32$ \\
\hline
\end{tabular}

Notas: variable dependiente $\ln$ (precio); VIF Variance inflation factor. El coeficiente beta corregido se expresa en porcentaje y se obtiene mediante la expresión [2] sugerida por Kennedy (24), representa el impacto sobre el precio ante un cambio de o a 1 en una variable ficticia, manteniendo constantes el resto de variables independientes. 